$52(14 \%)$ cases where doctors or nurses expressed concern from a child protection or welfare perspective. Only one case $(1.5 \%)$ was referred on to Tusla, the child protection service.

Conclusions The audit revealed that the assessment of child protection concerns in children presenting with burns is inadequate and this could result in less referrals to social work departments of vulnerable children. The frequency of child protection concerns in these children was surprisingly low in this audit.

\section{P2 CHAPERONS FOR CHILD PROTECTION MEDICAL EXAMINATIONS: A MISSING LINK?}

1,2Shashwat Saran*, 'Mahadeva Ganesh, 'Ezdihar Yousif. ' Shropshire Community Health NSH Trust, Shrewsbury, UK; ${ }^{2}$ Shrewsbury and Telford NHS Trust, Shrewsbury, UK

10.1136/archdischild-2019-epa.358

Background Child protection medical examinations should be undertaken in the presence of a chaperone. This as a good practice recommendation is clearly stated in the Child Protection companion.

Aim We undertook an audit of Child Protection medical examination reports to see if our practice meets the standards set by $\mathrm{RCPCH}$ in Child Protection companion.

Method Child protection companion's model report was chosen as the standard to compare our practices. Hospitalbased electronic patient records system (clinical portal) was used to review the reports by a single auditor. Twenty-eight reports were randomly selected. These children undertook Child Protection medical examination at a District General Hospital over a period of 14 months from January'2017 to February'2018.

Demographics Three-fourth were boys \& one-fourth were girls. Fifteen percent were under 1 year old, sixty percent were between $1 \& 5$ years old and twenty- five percent were over 5 years old.

Timeliness Three-fourth of the reports were typed within 72 hours of CP medical examination.

Quality All (100\%) the reports stated the source of information and recommendations made after assessment. Over threefourth reports stated informed consent was taken; included a brief introduction of the author and information about the growth centiles.

Two-third reports established that child's concerns were recorded. Reference to the evidence-based literature was made in fifteen percent of the reports.

Only seven percent of the reports stated use of Chaperones and amendments in the report after peer review meeting. Three percent of the reports stated both the time and date of referral.

Recommendations Our audit highlighted that Chaperons is an underused entity in child protection medical examinations. Chaperons are not only supposed to provide assurance to the child and family but also offers clinicians with an extra layer of protection in case of a complaint.

Thus we strongly advocate using Chaperon's in all cases of Child Protection Medicals unless declined by the child/family. In that case, this should be clearly documented. There is also a pressing need to improve the quality of overall documentation.

\section{P3 AN AUDIT ANALYSING PRESENTATION OF PAEDIATRIC BURNS TO AN URBAN PAEDIATRIC ACCIDENT, PATIENT DEMOGRAPHICS, CLINICAL AND SOCIAL OUTCOMES}

${ }^{1}$ Karen Kelleher*, ${ }^{1}$ Pauline Deacy, ${ }^{2}$ Susan Swan, ${ }^{1}$ Turlough Bolger. ${ }^{1}$ Paediatric Accident and Emergency Department, Tallaght University Hospital, Dublin, Ireland; ${ }^{2}$ Paediatric Social Work Department, Tallaght University Hospital, Dublin, Ireland

\subsection{6/archdischild-2019-epa.359}

Aims Analysis of paediatric burns, presentation, management and outcomes in an urban Accident and Emergency over the course of six months.

Methods The audit was undertaken in partnership with the paediatric social work department. Data on all presentations in a six month period (1/10/2017-31/03/2018) with a discharge diagnosis of burn or scald were included in the study. Data was collected on time and date of presentation, outcome of presentation from both a medical and social work point of view, medical and social work follow up arrangements including tertiary plastic team referral.

Results 70 cases were recorded. 66\% $(n=46)$ of patients were under the age of 5 years old, with a mean age of 4.6 years overall. $49 \%$ of cases presented between the hours of $6 \mathrm{pm}$ and $12 \mathrm{am}$.

In total 31 patients were referred to a tertiary centre for plastic surgery input: $24 / 31(77 \%)$ were referred non-urgently for next morning review and 7/31 (23\%) were transferred to the tertiary centre for same day review. 36/70 (51\%) received treatment from a nurse lead dressing clinic. Of these $3(4 \%)$ were subsequently referred onward for plastic surgery input.

During the time of the audit, all children under the age of 5 years $(n=46)$ were referred for social work review as a matter of routine. There were $52 / 70(74 \%)$ referrals to the social work department in the hospital, but only one case was referred on to Child protection services and the police. Of these referrals, $7 / 52(14 \%)$ had concern from a social protection point of view identified in the attendance documentation. In the equivalent six months of the previous year there was only a single case of a child presenting with a burn who was referred for initial social work review.

Conclusion This audit demonstrated that the imposing a blanket referral policy to social work for children with burns will increase the awareness of risk factors for child protection and result in improved multiagency assessment.

\section{P4 MECHANISM OF INJURY AND LENGTH OF STAY IN PAEDIATRIC RESUSCITATION BURNS >20\% TBSA: A TEN YEAR RETROSPECTIVE COHORT STUDY}

${ }^{1,2}$ Gerard McGuinness*, 1,2Maire Caitlin Casey, ${ }^{2}$ David O'Donovan. ${ }^{1}$ Royal College of Surgeons, St. Stephen's Green, Dublin, Ireland; 'Department of Plastic Surgery, Our Lady's Children's Hospital, Crumlin, Dublin, Ireland

\subsection{6/archdischild-2019-epa.360}

Thermal injuries represent a significant and common mechanism of accidental injury within the paediatric population. Thermal injuries over 10\% TBSA are often associated with poorer cosmetic, and psychological outcomes. Prolonged hospital stay, admission to an intensive care unit, as well as complex multidisciplinary approached to patient care are often required. With a greater TBSA, usually comes a greater burden of care. Here we present data from the National 